\title{
RETRACTED ARTICLE: Total spectral assignments and 2D NMR study of PVAc-b-PMA and PVAc-b-PMMA block copolymers
}

\author{
Mahdi Moeud Ajjalallah • \\ Mohammad Reza Rostami Daronkola
}

Received: 9 November 2010 / Accepted: 3 March 2011 /Published online: 19 April 2011

(C) Springer Science+Business Media B.V. 2011

This article has been retracted. Due to a dispute over authorship of the paper and ownership of the data, the Editor-in-Chief of the Journal of Polymer Research decided to retract the article "Total spectral assignments and 2D NMR study of PVAc-b-PMA and PVAc-b-PMMA block copolymers" by corresponding author Mohammad Reza Rostami Daronkola.

This article has been retracted. Due to a dispute over authorship of the paper and ownership of the data, the Editor-in-Chief of the Journal of Polymer Research decided to retract the article "Total spectral assignments and 2D NMR study of PVAc-b-PMA and PVAc-bPMMA block copolymers" by corresponding author Mohammad Reza Rostami Daronkola.

M. M. Ajjalallah • M. R. R. Daronkola ( $\bowtie)$

Polymer Engineering Group, Chemical Engineering Department, Tarbiat Modares University,

Jalal Al Ahmad Highway, P.O. Box 14115-143, Tehran, I.R, Iran

e-mail: mr_rostami@modares.ac.ir

M. R. R. Daronkola

e-mail: mmrrrostami@yahoo.com 